\title{
Head of household education level as a factor influencing whether delivery takes place in the presence of a skilled birth attendant in Busia, Uganda: a cross-sectional household study
}

Frédérique Vallières ${ }^{1 * \dagger}$, Alexandria Hansen ${ }^{1 \dagger}$, Eilish McAuliffe ${ }^{1}$, Emma Louise Cassidy ${ }^{1}$, Paul Owora ${ }^{2}$, Sam Kappler ${ }^{3}$ and Evelyn Gathuru ${ }^{3}$

\begin{abstract}
Background: Assistance during delivery by a skilled attendant is recommended as a means to reduce child and maternal mortality. Globally, higher levels of maternal education have been associated with better health behaviours at delivery. However, given that heads of households tend to be the decision makers regarding accessing healthcare, some educated mothers may find themselves prevented from accessing healthcare at the point of delivery.

Methods: We examined the association between head of household education level and health seeking behaviours at delivery across a sample of 392 households. Chi-squared analysis and odds ratios were calculated to measure the strength of the relationship between no, some primary, or some secondary or higher education attained by the head of household and the presence or absence of a skilled birth attendant at that child's birth, and whether the birth took place at a health facility.

Results: Heads of household $(n=392)$ were predominantly male $(93.4 \%$ [(90.9\%, 95.8\%), a $=0.05])$. We found a significant difference in skilled birth attendance between heads of households with some primary education and heads of household with some secondary education or higher $\left(x^{2}(1)=6.231, p<0.05\right)$ whereby those with secondary or higher education were significantly more likely to seek a skilled birth attendant $(\mathrm{OR}=1.5,[1.1,2.1])$. The difference in health centre delivery between heads of household with a primary education and heads of household with a secondary or higher education was also significant $\left(x^{2}(1)=7.519, p<0.05\right)$. Those with secondary or higher education were significantly more likely to deliver in a health facility $(\mathrm{OR}=1.6,[1.2,2.1])$.

Conclusions: The results of our analysis, which identified the vast majority of heads of households as men, suggests that education, or rather limited or a lack of education for the head of household, may be a barrier to women's use of health care in Uganda and therefore reinforces the need to increase educational access among male heads of households. Improving the rates of health centre deliveries and utilization of services provided by skilled health workers might lie, in part, in increasing overall education levels of heads of households, specifically the education of male heads of households.
\end{abstract}

Keywords: Skilled birth attendant, Health-centre delivery, Head of household, Education

\footnotetext{
* Correspondence: vallierf@tcd.ie

${ }^{\dagger}$ Equal contributors

${ }^{1}$ Centre for Global Health, Trinity College Dublin, 7-9 Leinster Street South,

Dublin 2, Ireland

Full list of author information is available at the end of the article
} 


\section{Background}

Deliveries attended by skilled providers such as nurses, doctors, or midwives, in hygienic conditions, can significantly reduce the risk of complications known to cause death or serious illness in both mothers and their children [1-8]. Increasing the number of women who seek a skilled birth attendant (SBA) remains one of the primary means advocated by the World Health Organization (WHO) to reduce maternal and neonatal mortality [9]. The last two decades have seen an increase in the rate of births assisted by SBAs worldwide, except in subSaharan Africa, where barriers still prevent women from accessing SBAs [10]. Such barriers include: lack of transportation, distance from the health centre, cost of travel and health services, perceived low-quality of care in facilities, unavailability of emergency obstetric care at health centres, and cultural barriers including women's inability to travel alone and their adherence to traditional practices [2,11-15].

Uganda continues to rank among the countries with the highest maternal and child mortality. With an estimated Maternal Mortality Ratio (MMR) of 438/100,000 and an under five mortality rate of 90 per 1,000 live births, Uganda is not expected to meet Millennium Development Goals four or five $[16,17]$. The greatest risk of child death occurs around the time of birth and neonatal deaths in Uganda are estimated to account for nearly $53 \%$ of all infant deaths $[17,18]$. Despite important progress, the country's most recent demographic health survey revealed that only $53 \%$ of births in rural areas were attended by skilled health personnel [17]. In Uganda's Eastern region, $39.6 \%$ of births were accompanied by an unskilled assistant such as a traditional birth attendant (TBA), a relative or a friend, and $7.7 \%$ of births received no assistance at all [17].

Heads of households, who in most contexts tend to be predominantly male [19], often act as key decision makers in accessing skilled healthcare at the time of delivery and recent research suggests that husband-only decision making is negatively associated with skilled delivery care [20]. Specifically, men often provide the financial means, transport, and sometimes the permission for women to attend a health centre [12,15]. In Eastern Uganda, $58 \%$ of women delivering in a health facility were accompanied by their husband or partner [21]. Though it is widely agreed that men should be more involved in the continuum of care provided to pregnant women, research on how to best incorporate them in Uganda is lacking [22-25].

It is well established that maternal education is an important factor in improving child health outcomes, along with increasing overall household access to skilled healthcare. In Uganda, the neonatal mortality rate of infants whose mother had a primary education was found to be $10 \%$ lower than that of infants whose mother had no education [21]. Likewise, a study conducted in Entebbe, Uganda found that less educated mothers were more likely to give birth in the presence of an unskilled assistant or worse, with no assistance at all [11]. Globally, higher levels of maternal education have been associated with, amongst other things, increased knowledge and acceptability of vaccinations, better child immunization status, more consistent attendance of antenatal care visits, greater institutional deliveries, and reduced risk of neo-natal and post-neonatal deaths [11,26-29]. However, given that heads of households tend to be the decision makers regarding accessing healthcare, some educated young women and mothers may find themselves prevented from accessing healthcare. Previous studies have focused on the importance of maternal education and the important role heads of households (HOHs) play in accessing health care at delivery in Uganda.

\section{Methods}

This paper first examines whether the education of the head of household (predominantly male and the key decision maker in Ugandan households) is associated with health seeking behaviours at time of delivery in Busia, Uganda. Where an association was found, we also further explore the strength of that association.

The secondary data obtained for this paper were collected as part of a baseline assessment of maternal and child health in the sub-counties of Busitema, Sikuda, Lunyo, and Busiime, located in Uganda's Busia District, during June and July of 2011. World Vision Ireland and World Vision Uganda conducted the baseline in preparation for the implementation of a community-based maternal and child health programme using community health workers to target changes in household health behaviour. Bordering Kenya to the east and Tanzania to the south and formally known as Tororo District, Busia District has an estimated population of approximately 287,800 inhabitants [30].

\section{Sampling}

The baseline exercise employed a cross-sectional household survey, which was conducted across a sample of 400 households located in four sub-counties of Busia. A two-stage probability sampling method was used to obtain a sample of the population in each parameter. Village lists were obtained for the sub-counties of Busitema, Sikuda, Lunyo, and Busiime. The probability of a village being selected was set as proportional to the number of households within that village. All households therefore had an equal chance of being selected regardless of whether they contained the target population or not. 
In the second stage of sampling, village leaders led field teams to the village centre where a pen was spun to determine the field team's walking direction. A random number generation table was subsequently used to decide which household was to be visited first. A total of 407 households, from 125 out of the possible 136 villages, were ultimately visited in the sample, 400 of which completed the questionnaire. Sample size was calculated assuming a confidence level of 95\% $(\mathrm{a}=0.05)$.

\section{Survey tool}

The survey tool was adapted from the Ministry of Health's $(\mathrm{MOH})$ own village health team (VHT)/ICCM Register 2010 [31] and developed in consultation with the district health management team in Busia (Additional file 1). Though the questionnaire was printed in English, training was conducted in a mixture of English and Luganda. VHTs were permitted to conduct the interview in whichever language they felt best suited the household.

The household was defined in terms of any people who were co-resident and shared common cooking arrangements, and were able to recognise one person as the head of household [32]. Participants in each household were asked to identify the $\mathrm{HOH}$, and that individual's most recently completed education level. Participants were then asked to identify all children under the age of 5 within that household and the child's relation to the $\mathrm{HOH}$. For each child, subsequent questions determined the location of their birth (at a health centre or elsewhere), as well as who was present at the time of birth: a skilled provider, unskilled provider such as a TBA, both, or neither. Aligned with Ugandan $\mathrm{MOH}$ policy, a skilled provider was defined as a "doctor, nurse, midwife, medical assistant, or clinical officer" [21].

\section{Exclusion and inclusion criteria}

To be considered for secondary analysis a household had to contain at least one child under the age of 60 months. Interviews were primarily conducted with the child's primary caregiver. A primary caregiver was defined as the person who was, "primarily responsible for the health, safety and comfort of that child". A total of 392 out of 400 de-identified households were included in the analysis.

\section{Ethical considerations}

Informed written consent was obtained from all participants. If the participant was illiterate, signatures were obtained in the form of a fingerprint using an inkpad. Permission for the Centre for Global Health, Trinity College Dublin to use the de-identified baseline data for secondary analysis was obtained from both World Vision Ireland and World Vision Uganda and ethical approval was obtained from the Health Policy and Management/
Centre for Global Health Research Ethics committee, Trinity College Dublin.

\section{Data analysis}

Quantitative analysis was conducted using PASW Statistics 18 (Release Version 18.0.0) and SPSS Statistics 17 (Release Version 17.0.0). Delivery practices were statistically analyzed according to relevant demographic variables. Respondent's level of education was recorded as the highest grade or year completed by that individual. For analysis, these were categorised as follows: no form of education; attained any level of primary education; or, attained any form of secondary or higher education. Both education levels and delivery practices were compared across age and gender to ensure comparability and to identify any possible confounders or effect modifiers. Descriptive tests and Chi-Square/Correlation analysis were used to demonstrate the effects of the independent variables on the probability of choosing a health centre facility for delivery, rather than remaining at home or outside a clinical setting for delivery. The effects of the independent variable on the probability of choosing assistance from a trained, skilled birth attendant versus opting for a traditional home delivery without trained assistance were also presented.

Pearson Chi-Square tests were conducted to measure the significance of the relationship between the education level attained by the $\mathrm{HOH}$ and the presence of an SBA or TBA (or other unskilled birth attendant) at that child's birth, as well as whether the birth took place at a health facility. Additional Chi-Square tests of independence were individually executed on each possible combination of the groups. Where a statistically significant relationship was found, odds ratios were calculated with the lower education level as reference. Analysis was first conducted for children who were labeled as biologically related to the $\mathrm{HOH}$. Biologically related children included only sons and daughters of the $\mathrm{HOH}$. This same analysis was subsequently conducted for all children who were either biologically linked or relatively linked to the $\mathrm{HOH}$. Relative children included nieces, nephews, stepchildren, and grandchildren. All tests were conducted for $95 \%$ confidence with $\alpha=0.05$.

\section{Results}

\section{Characteristics of sample}

HOHs in Busia $(n=392)$ were predominantly male $(93.4 \%[(90.9 \%, 95.8 \%)])$, with $71.2 \%$ of male $\mathrm{HOHs}$ aged 18 to 39 years $([66.6 \%, 75.9 \%])$. Of the $\mathrm{HOHs}$ who responded to the education level question $(n=373)$, $5.6 \%$ had no form of education ([3.3\%, 8.0\%]), 58.7\% had achieved some level of primary education [53.7\%, $63.7 \%]$ ), and $35.7 \%$ had completed at least some secondary level education or higher [30.8\%, 40.5\%]). Gender 
was related significantly to $\mathrm{HOH}$ education level $\left(\chi^{2}(2)=\right.$ $59.751, \mathrm{p}<0.05)$, as was age $\left(\chi^{2}(2)=6.761, \mathrm{p}<0.05\right)$, however neither of these factors was associated with attendants at delivery (SBA v. TBA) or place of delivery (health centre v. other). Adjustment via multinomial logistic regression was considered for age and gender of the $\mathrm{HOH}$ as both were associated with education level attained, however it had no effect on the outcome as neither were associated with delivery practices and indeed reduced the reliability of the model. The groups were therefore comparable with no need for adjustment by age or by gender.

Overall, $34.1 \%$ of the children under the age of five in Busia $(n=781)$ were delivered in the presence of a skilled provider $([30.7 \%, 37.4 \%])$. In comparison, $57.4 \%$ of children under-five's births $(\mathrm{n}=779)$ were assisted by an unskilled provider (i.e. TBA) $([53.9 \%, 60.9 \%])$, and 9.1\% of children were delivered in the absence of any type of birth attendant $([7.1 \%, 11.1 \%], \mathrm{n}=779)$. Moreover, $37.9 \%$ of children $(n=781)$ were born in a health care facility $([34.5 \%, 41.3 \%])$, while $62.1 \%$ were born elsewhere $([58.7 \%, 65.5 \%])$.

\section{Relationship between $\mathrm{HOH}$ education level and assistance} at birth of children biologically related to $\mathrm{HOH}$

For biologically related children, differences were observed in the utilisation of an SBA between HOHs with no education, those with primary education, and those with a secondary or higher education, see Figure 1. The ChiSquare test of independence revealed that the difference was statistically significant $\left(\chi^{2}(2)=8.646, p<0.05\right)$. We found a significant difference in SBA attendance between $\mathrm{HOHs}$ with primary education and $\mathrm{HOH}$ with secondary or higher education $\left(\chi^{2}(1)=6.231, p<0.05\right)$ whereby those with secondary or higher education were significantly more likely to seek an SBA $(\mathrm{OR}=1.5,[1.1,2.1])$. The higher the education level the more likely the child's birth had been attended by an SBA. The difference in SBA attendance between $\mathrm{HOH}$ with no education and $\mathrm{HOHs}$ with primary education was not statistically significant.

Differences were also observed in utilization of unskilled birth attendants, such as TBAs, between $\mathrm{HOHs}$ with no education, with primary education, and those with secondary or higher education, see Figure 2. The Chi-Square test of independence revealed that the difference was statistically significant $\left(\chi^{2}(2)=12.296, p<0.05\right)$. The difference in unskilled attendance between $\mathrm{HOHs}$ with no education and $\mathrm{HOHs}$ with secondary or higher education was statistically significant $\left(\chi^{2} \quad(1)=4.768, p<0.05\right)$ whereby those with secondary or higher education were significantly less likely to seek an unskilled attendant $(\mathrm{OR}=0.3,[0.1,0.8])$; the difference in unskilled attendance between $\mathrm{HOHs}$ with primary education and $\mathrm{HOHs}$ with secondary or higher education was statistically significant $\left(\chi^{2}(1)=8.646, p<0.05\right)$ whereby those with secondary or higher education were significantly less likely to seek an unskilled attendant $(\mathrm{OR}=0.6,[0.5,0.8])$; the difference in unskilled attendance between $\mathrm{HOHs}$ with no education and $\mathrm{HOHs}$ with primary education was not statistically significant.

Observed differences in whether the delivery took place at a healthcare facility for $\mathrm{HOHs}$ with no education, primary education, and those with secondary or higher education are depicted in Figure 3. The Chi-Square test of independence revealed that the difference was statistically significant $\left(\chi^{2}(2)=11.256, p<0.05\right)$. The difference in health centre delivery between $\mathrm{HOHs}$ with no education and $\mathrm{HOH}$ with secondary of higher education was statistically significant $\left(\chi^{2}(1)=4.590, p<0.05\right)$ whereby those with secondary or higher education were significantly more likely to deliver in a health facility $(\mathrm{OR}=3.2$,

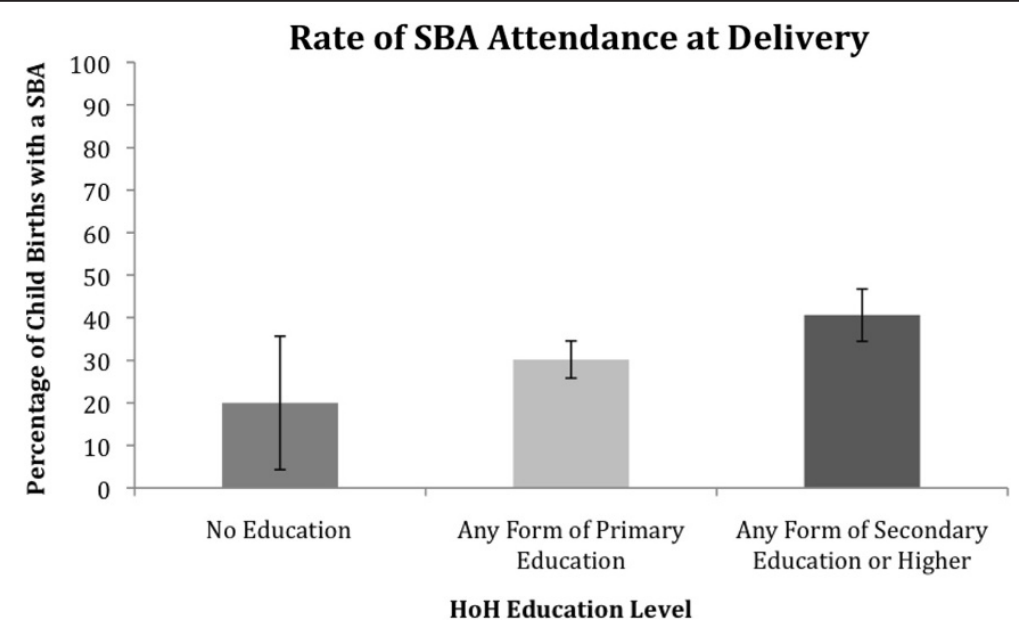

Figure 1 The utilisation of a skilled birth attendant during the birth of a child biologically related to the HoH according to the education level of that $\mathrm{HoH}$. 


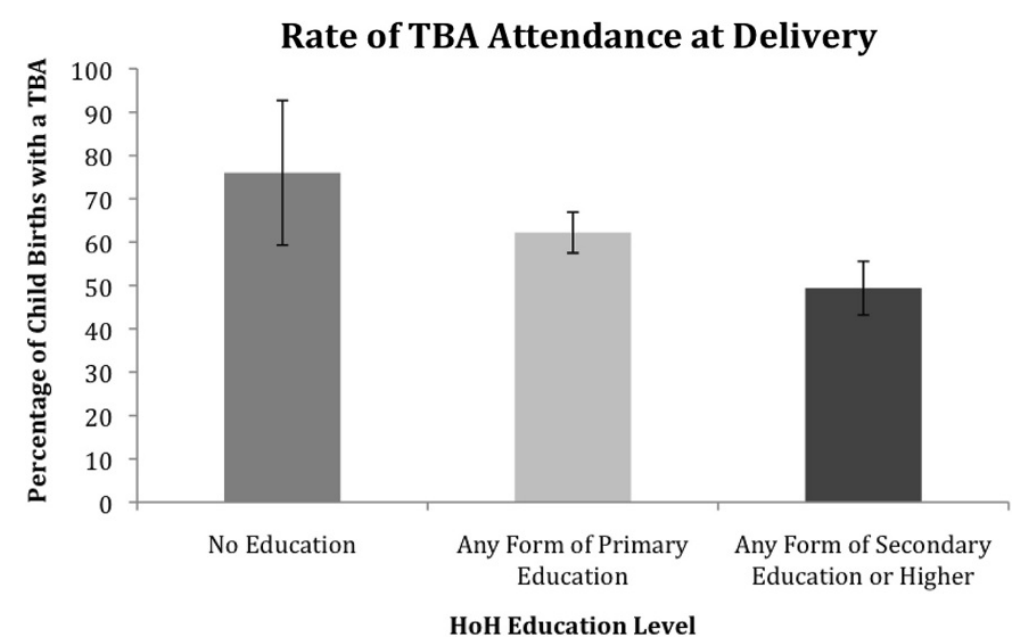

Figure 2 The utilisation of a traditional/unskilled birth attendant during the birth of a child biologically related to the HoH according to the education level of that $\mathrm{HoH}$.

$[1.2,8.9])$; the difference in health centre delivery between $\mathrm{HOHs}$ with primary education and $\mathrm{HOHs}$ with secondary or higher education was statistically significant $\left(\chi^{2}(1)=\right.$ $7.519, p<0.05)$ whereby those with secondary or higher education were significantly more likely to deliver in a health facility $(\mathrm{OR}=1.6,[1.2,2.1])$; and the difference in health centre delivery between $\mathrm{HOHs}$ with no education and $\mathrm{HOHs}$ with primary education was not statistically significant.

Relationship between $\mathrm{HOH}$ education level and assistance at birth of children (biological and relative) under-five in household

For all children, including biological and relative children, similar differences were observed in SBA attendance unskilled attendance and health centre delivery between $\mathrm{HOHs}$ differentiated by education levels. The Chi-Square test of independence revealed that differences in SBA attendance according to education level were statistically significant $\left(\chi^{2}(2)=8.70, p<0.05\right)$; differences in unskilled attendance were statistically significant $\left(\chi^{2}(2)=13.223, p<0.05\right)$; and delivery rates at a health centre were statistically significant $\left(\chi^{2}(2)=\right.$ 14.062, $p<0.05)$.

The difference in SBA attendance between $\mathrm{HOH}$ with no education and $\mathrm{HOH}$ s with secondary or higher education was not statistically significant; the difference in SBA attendance between $\mathrm{HOH}$ with primary education and $\mathrm{HOH}$ with secondary or higher education was statistically significant $\left(\chi^{2}(1)=7.908, p<0.05\right)$ whereby those with secondary or higher education were significantly more likely to seek a skilled attendant $(\mathrm{OR}=1.6$,

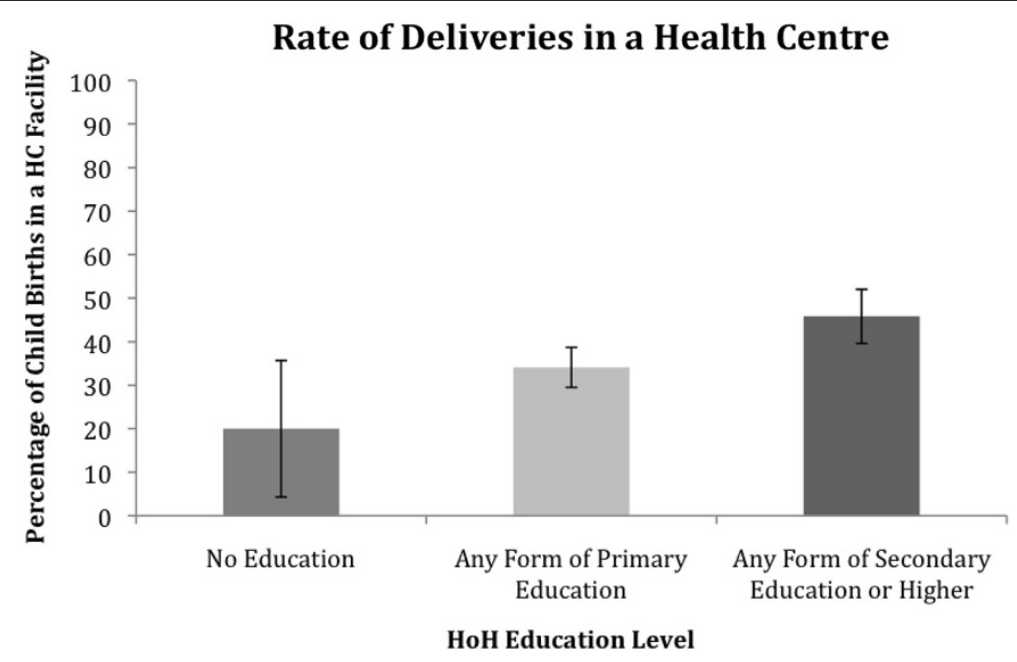

Figure 3 Births in a health care facility for children biologically related to the $\mathrm{HoH}$ according to the education level of that $\mathrm{HoH}$. 
[1.2,2.2]); and the difference in SBA attendance between $\mathrm{HOHs}$ with no education and $\mathrm{HOHs}$ with primary education was not statistically significant.

Neither the difference in presence of an unskilled birth attendant between $\mathrm{HOHs}$ with no education and $\mathrm{HOHs}$ with secondary or higher education nor the difference in presence of an unskilled birth attendant between $\mathrm{HOHs}$ with no education and those with primary education were found to be significant. However, the difference in the presence of an unskilled birth attendant between $\mathrm{HOHs}$ with primary education and $\mathrm{HOHs}$ with secondary or higher education was significant $\left(\chi^{2}(1)=10.442, p<0.05\right)$ whereby those with secondary or higher education were significantly less likely to seek assistance from unskilled personnel $(\mathrm{OR}=0.6,[0.5,0.8])$. The difference in health centre delivery between $\mathrm{HOHs}$ with no education and $\mathrm{HOHs}$ with secondary or higher education was statistically significant $\left(\chi^{2}(1)=5.727, p<0.05\right)$ - those with secondary or higher education were significantly more likely to deliver in a health facility $(\mathrm{OR}=2.6,[1.2,5.6])$; the difference in health centre delivery between $\mathrm{HOHs}$ with primary education and $\mathrm{HOHs}$ with secondary or higher education was statistically significant $\left(\chi^{2}(1)=10.425, p\right.$ $<0.05)$ whereby those with secondary or higher education were significantly more likely to deliver in a health facility $(\mathrm{OR}=1.7,[1.3,2.3])$; and the difference in health centre delivery between $\mathrm{HOHs}$ with no education and $\mathrm{HOHs}$ with primary education was not statistically significant.

Overall, our analysis shows that there is an association as well as a significant effect between education level of the $\mathrm{HOH}$ and health-seeking behaviour at the time of delivery.

\section{Discussion}

Children born in households in which the $\mathrm{HOH}$ had an education level beyond that of primary education were more likely to be born in a health facility and in the presence of a skilled provider. Specifically, a child whose $\mathrm{HOH}$ had some form of secondary or higher education sought health services for delivery at significantly higher rates than either those born in households in which the $\mathrm{HOH}$ had only a primary education or those born in households in which the $\mathrm{HOH}$ had no education. Our results further indicate that simply attaining a primary education did not have a significant impact on the rates of SBA attendance and health centre deliveries. Regardless of the child's relationship to the $\mathrm{HOH}$, whether biological or relative, the observed association relating to education remained significant.

The association between education and health behaviours reinforces the significant role that education plays in improving utilisation of maternal health services. Though the relationship between a mother's education level and delivery practices is well established throughout the existing literature, this study suggests that the education level of the decision maker (i.e. head of household) is also a significant factor in women's utilisation of health services. Given that one of the primary international recommendations for reducing maternal and child mortality is increasing access to skilled health providers, prioritization in Uganda needs to be given to increasing health centre attendance through increasing education [33]. Specifically, emphasis is needed on promoting education for those who are thought to play a critical role in the health behaviour decision-making process. In Uganda, where the majority of households are headed by men, this means not just focusing on young girls and women's education, but also educating young men as future $\mathrm{HOHs}$, and thus key decision makers on access to maternal health care.

A study conducted in Uganda's southern Rakai district, found that women who felt that attending the health centre was their decision alone were reportedly more likely to deliver in health units compared to those who said that attending health centres depends on their husbands [12]. Current strategies in Uganda tend to primarily focus on women, even though it is often men who provide the financial support and play an influential role in the health-seeking process [15].

The results of our study, which identified the vast majority of $\mathrm{HOHs}$ as men, suggests that education, or rather limited or a lack of education, may be a barrier to the use of health care in Uganda and therefore reinforces the need to increase educational access among male $\mathrm{HOHs}$. It is unclear however, whether higher male education levels mediate better health seeking behaviours at the time of delivery through providing women with information as well as more control over their decision on where to access health care, or through greater male dominance. Education levels for male $\mathrm{HOHs}$ may increase access to skilled deliveries particularly where fees might be incurred because male $\mathrm{HOHs}$ have greater control over household finances and can accordingly manage and regulate the seeking of health services [34]. Though level of income was not quantified in the survey, greater levels of education could account for greater household income, and those with higher incomes are more likely to seek access to healthcare services [35]. The availability of TBAs, that they are often from the same locality, and decreased financial costs associated a TBA assisted delivery, must also be considered as factors influencing the preference of TBAs at the point of delivery in Uganda [36]. Secondary data obtained being largely quantitative, we were unable to account for the influence of cultural and religious beliefs on delivery services in our analysis, which acts as a limitation to our study. Similarly, the secondary data obtained only recorded the relationship between children under-five to the $\mathrm{HOH}$, implying that we were unable to link delivery practices to educational levels of mothers. 
While maternal education has been identified as a factor influencing health centre births and overall utilisation of maternal health services, strengthening the education of male $\mathrm{HOHs}$ may be equally, if not more, important in improving child and maternal health in Uganda. More explorative studies describing the pathways and examining the processes through which male $\mathrm{HOH}$ education influences whether or not a woman gives birth in the presence of a skilled birth attendant are necessary. As with previous studies, which found an association between higher rates of male attendance at antenatal clinics and higher levels of education, and with reviews showing that a lack of paternal involvement negatively affected pregnancy outcomes, there is a need to increase male participation in both education and maternal and child health promotion programmes [23,37]. As millions of women within South Asia and subSaharan Africa continue to give birth without an SBA over the next few years [38], a more educated, more knowledgeable $\mathrm{HOH}$ is likely to be a critical component in overcoming existing barriers and further increasing the percentage of births attended by skilled birth attendants.

\section{Conclusions}

Access to high quality maternal and child health services are essential to lowering maternal and child mortality. However, more attention should be paid to the household factors that may mediate access to such health services. Strategies to increase education levels amongst men, combined with providing men with access to knowledge about maternal and child health services may contribute to increasing skilled attendance at delivery, and to the improvement of maternal health outcomes overall.

\section{Additional file}

\section{Additional file 1: Household register.}

\section{Abbreviations}

SBA: Skilled birth attendant; TBA: Traditional birth attendant; $\mathrm{HOH}$ : Head of household; MMR: Maternal mortality ratio; VHT: Village health team.

\section{Competing interests}

The authors declare that they have no competing interests.

\section{Authors' contributions}

FV \& AH initiated the concept for the use of the data, came up with the analysis plan, and co-wrote the manuscript. AH conducted the data analysis and FV contributed towards the design. EM reviewed and provided substantial inputs into the manuscript review. ELC provided thorough statistical review and further data analysis. PO, EG \& SK played key roles in the tool development, implementation, and data collection phases. All authors read, provided substantial input, and approved the final manuscript. FV is the final guarantor of the paper. All authors read and approved the final manuscript.

\section{Acknowledgements}

We are grateful to the Busia District Medical Officer, Dr. Bwire Oundo and health workers from the Busia District for their cooperation during the designing and implementation of the study. We would also like to extend our sincere thanks to Robert Kanwagi and Justin Iranya, the World Vision Uganda National Office, Sheila Garry \& Magnus Conteh for their active contribution to the review of this manuscript. The team is grateful for the support of Irish Aid and the people of Ireland for funding this work through the "Access to Infant and Maternal Health Programme" (AlM-Health), a collaborative initiative with World Vision Ireland and the Centre for Global Health, Trinity College Dublin.

\section{Author details}

${ }^{1}$ Centre for Global Health, Trinity College Dublin, 7-9 Leinster Street South, Dublin 2, Ireland. ${ }^{2}$ World Vision Uganda, World Vision Uganda, Kisozi Complex, Kampala, Uganda. ${ }^{3}$ World Vision Ireland, The Mews, Rathmines Park, Dublin 6, Ireland.

Received: 13 April 2012 Accepted: 14 February 2013

Published: 21 February 2013

\section{References}

1. Portela A, Santarelli C: Empowerment of women, men, families and communities: true partners for improving maternal and newborn health. Br Med Bull 2003, 67(1):59-72

2. Parkhurst JO, Rahman SA, Ssengooba F: Overcoming access barriers for facility-based delivery in low-income settings: insights from Bangladesh and Uganda. J Health Popul Nutr 2006, 24(4):438-445.

3. Wandabwa J, Doyle P, Todd J, Ononge S, Kiondo P: Risk factors for severe post partum haemorrhage in Mulago hospital, Kampala, Uganda. East Afr Med J 2008, 85(2):64-71.

4. Graham WJ, Bell J, Bullough CHW: Can skilled attendance at delivery reduce maternal mortality in developing countries? Studies in Health Service Organization Policy 2001, 17:97-130.

5. de Bernis L, Sherratt DR, AbouZahr C, Van Lerberghe W: Skilled attendants for pregnancy, childbirth and postnatal care. Br Med Bull 2003, 67:39-57.

6. Koblinsky MA, Campbell O, Heichelheim J: Organizing delivery care: what works for safe motherhood? Bull World Health Organ 1999, 77(5):399-406.

7. De Brouwere V, Tonglet R, Van Lerberghe W: Strategies for reducing maternal mortality in developing countries: what can we learn from the history of the industrialized West? Trop Med Int Health 1998, 3(10):771-782.

8. Kwast BE: Reduction of maternal and perinatal mortality in rural and peri-urban settings: what works? Eur J Obstet Gynecol Reprod Biol 1996, 69(1):47-53.

9. WHO: In Making pregnancy safer: the critical role of the skilled attendant. Edited by Research DoRHa. Geneva: World Health Organization; 2004:24.

10. UNSD: Statistical Annex: Millennium Development Goals Indicators. In United Nations Statistics Division; 2011. http://millenniumindicators.un.org/ unsd/mdg/Search.aspx?q=skilled\%20birth\%20attendance.

11. Tann CJ, Kizza M, Morison L, Mabey D, Muwanga M, Grosskurth H, Elliott AM: Use of antenatal services and delivery care in Entebbe, Uganda: a community survey. BMC Pregnancy Childbirth 2007, 7:23.

12. Amooti-Kaguna B, Nuwaha F: Factors influencing choice of delivery sites in Rakai district of Uganda. Soc Sci Med 2000, 50(2):203-213.

13. Mbonye AK, Asimwe JB: Factors associated with skilled attendance at delivery in Uganda: results from a national health facility survey. Int J Adolesc Med Health 2010, 22(2):249-255.

14. Kyomuhendo GB: Low use of rural maternity services in Uganda: impact of women's status, traditional beliefs and limited resources. Reprod Health Matters 2003, 11(21):16-26.

15. Waiswa P, Kemigisa M, Kiguli J, Naikoba S, Pariyo GW, Peterson S: Acceptability of evidence-based neonatal care practices in rural Uganda - implications for programming. BMC Pregnancy Childbirth 2008, 8:21.

16. Ayiko R, Antai D, Kulane A: Trends and determinants of under-five mortality in Uganda. East Afr J Public Health 2009, 6(2):136-140.

17. UBOS: In Uganda Demographic and Health Survey 2011 Preliminary Report. Edited by UBOS. Kampala: ICF International; 2012.

18. Lawn JE, Kerber K, Enweronu-Laryea C, Massee Bateman O: Newborn survival in low resource settings-are we delivering? BJOG 2009, 116(Suppl 1):49-59. 
19. Kishor S, Neitzel K: In The Status of Women: Indicators for Twenty-Five Countries. Edited by Studies DC. Calverton, Maryland: Macro International Inc; 1996.

20. Story WT, Burgard SA: Couples' reports of household decision-making and the utilization of maternal health services in Bangladesh. Soc Sci Med 2012, 75(12):2403-2411.

21. UBOS: In Uganda Demographic and Health Survey 2006. Edited by Statistics UBo. Kampala: Macro International Inc; 2007.

22. Roth DM, Mbizvo MT: Promoting safe motherhood in the community: the case for strategies that include men. Afr J Reprod Health 2001, 5(2):10-21.

23. Alio AP, Salihu HM, Kornosky JL, Richman AM, Marty PJ: Feto-infant health and survival: does paternal involvement matter? Matern Child Health J 2010, 14(6):931-937.

24. Katz DA, Kiarie JN, John-Stewart GC, Richardson BA, John FN, Farquhar C: Male perspectives on incorporating men into antenatal HIV counseling and testing. PLoS One 2009, 4(11):e7602.

25. Sternberg P, Hubley J: Evaluating men's involvement as a strategy in sexual and reproductive health promotion. Health Promot Int 2004 19(3):389-396.

26. Bhuiya A, Bhuiya I, Chowdhury M: Factors affecting acceptance of immunization among children in rural Bangladesh. Health Policy Plan 1995, 10(3):304-312.

27. Nankabirwa V, Tylleskar T, Tumwine JK, Sommerfelt H: Maternal education is associated with vaccination status of infants less than 6 months in Eastern Uganda: a cohort study. BMC Pediatr 2010, 10:92.

28. Titaley CR, Dibley MJ, Roberts CL: Type of delivery attendant, place of delivery and risk of early neonatal mortality: analyses of the 1994-2007 Indonesia Demographic and Health Surveys. Health Policy Plan 2011, 27(5):003405-003416.

29. Agha S, Carton TW: Determinants of institutional delivery in rural Jhang, Pakistan. Int J Equity Health 2011, 10:31.

30. UBOS: Busia District Population 2002; 2002. http://wwwubosorg. Kampala.

31. Uganda MoH: In VHT/ICCM Register. Edited by Health Mo. Kampala: Ministry of Health Uganda; 2010.

32. UNSD: In Designing household survey samples: practical guidelines. Edited by Affairs DfEaS. New York: United Nations; 2005.

33. Parkhurst JO, Penn-Kekana L, Blaauw D, Balabanova D, Danishevski K Rahman SA, Onama V, Ssengooba F: Health systems factors influencing maternal health services: a four-country comparison. Health Policy 2005, 73(2):127-138

34. Ekirapa-Kiracho E, Waiswa P, Rahman MH, Makumbi F, Kiwanuka N, Okui O, Rutebemberwa E, Bua J, Mutebi A, Nalwadda G, et al: Increasing access to institutional deliveries using demand and supply side incentives: early results from a quasi-experimental study. BMC Int Health Hum Rights 2011 11(Suppl 1):11.

35. Castro-Leal F, Dayton J, Demery L, Mehra K: Public spending on health care in Africa: do the poor benefit? Bull World Health Organ 2000, 78(1):66-74.

36. Keri L, Kaye D, Sibylle K: Referral practices and perceived barriers to timely obstetric care among Ugandan traditional birth attendants (TBA). Afr Health Sci 2010, 10(1):75-81.

37. Tweheyo R, Konde-Lule J, Tumwesigye NM, Sekandi JN: Male partner attendance of skilled antenatal care in peri-urban Gulu district, Northern Uganda. BMC Pregnancy Childbirth 2010, 10:53.

38. Crowe S, Utley M, Costello A, Pagel C: How many births in sub-Saharan Africa and South Asia will not be attended by a skilled birth attendant between 2011 and 2015? BMC Pregnancy Childbirth 2012, 12:4.

doi:10.1186/1471-2393-13-48

Cite this article as: Vallières et al: Head of household education level as a factor influencing whether delivery takes place in the presence of a skilled birth attendant in Busia, Uganda: a cross-sectional household study. BMC Pregnancy and Childbirth 2013 13:48.

\section{Submit your next manuscript to BioMed Central and take full advantage of:}

- Convenient online submission

- Thorough peer review

- No space constraints or color figure charges

- Immediate publication on acceptance

- Inclusion in PubMed, CAS, Scopus and Google Scholar

- Research which is freely available for redistribution

Submit your manuscript at www.biomedcentral.com/submit
Biomed Central 